and exchange views, and on this occasion the various nationalities came together with a common objective. Representatives from the Dominions Overseas appreciated to the full the value of the Congress as an opportunity to meet their colleagues. The Congress also demonstrated to those countries which are lagging behind in the encouragement of scientific work the benefits accruing from organized research.

During the period of the Congress, meetings of some of the commissions functioning under the auspices of the Institut International du Froid were convened. Commission No. 1 considered the question of temperature measurements down to liquid hydrogen temperatures. The temperature scale is defined by international agreement down to the boiling point of oxygen; beyond this there is no generally accepted standard scale. Even in the range covered by the International Scale, further work appears to be necessary, since some investigators have found that platinum thermometers constructed and calibrated according to specification differ by so much as $0.03^{\circ}$ at about

$140^{\circ} \mathrm{C}$. To study this question, it was decided to set up a committee composed of representatives of the various national laboratories and of those centres where low temperature investigations are in progress.

Commission No. 12 on land transport and Commission No. 13 on water transport held a joint session. As problems for further study, they decided that data should be collected as to the heat production of various types of fruit, this being a matter of interest to the marine engineer when dealing with fruit delivered to the ship without pre-cooling. It was also decided to consider methods for the control of the atmospheric conditions in the holds of ships carrying perishable produce requiring atmospheres of high carbon dioxide and low oxygen content.

These are subjects which will be studied by expert committees under the auspices of the Institut International du Froid and reported upon at the next Congress.

Thanks to the thorough planning of the executive committee, the arrangements worked smoothly and efficiently, and those participating will retain the most pleasant memories of a very useful meeting.

\title{
The Royal Research Ship Research
}

\author{
By Dr. H. Spencer Jones, F.R.S., Astronomer Royal
}

$\mathrm{T}$ HE destruction of the non-magnetic ship Carnegie by an explosion, at Apia, Western Samoa, on November 29, 1929, brought to a sudden end the magnetic survey of the oceanic areas, which had been carried on for twenty-five years by the Carnegie Institution of Washington. The Carnegie had been specially designed and constructed for obtaining magnetic observations at sea. She was a hermaphrodite brig, built of white oak and pine, with copper or bronze fastenings, and with a displacement of 568 tons. She was equipped with an auxiliary engine, capable of giving a speed of about 6 knots in calm weather ; the engine was of internal combustion type and, at first, used gas generated from solid fuel, but, as this proved not altogether satisfactory, petrol was substituted. Sufficient fuel was carried to give a cruising range of 2,000 miles at 6 knots. With the exception of cast-iron pistons for the cylinders of the engine and the steel cams necessary for operating the valves, amounting in all to less than $600 \mathrm{lb}$., no magnetic material was used in the construction of the ship.

In six cruises between 1909 and 1921, the Carnegie traversed 252,702 miles in 3,267 days actually at sea. Her last cruise was planned to extend from May 1928 to September 1931 and to cover 110,000 miles. It was designed to determine the secular change of the earth's magnetism in all oceans, by making numerous intersections with the tracks of previous cruises. Nearly one half of this cruise had been completed at the time of her loss.

The results obtained by the Carnegie were placed freely and promptly by the Carnegie Institution at the disposal of the British and other Governments, for use in the construction of world magnetic charts. Successive issues of these charts were based to an increasing extent upon the data provided by the Carnegie.

The secular changes of the magnetic elements at any given place are not constant quantities. Extrapolation over long periods may therefore lead to considerable errors. The continual accumulation of observations is necessary in order to determine both the secular change and the rate of change of the secular change of each element. At the present time, the magnetic data are most uncertain in the Indian Ocean. The last cruise of the Carnegie in the Indian Ocean was in the year 1919. The 
cruise on which she was engaged at the time of her destruction was to have taken her into the Indian Ocean in 1930 and 1931. In South Africa there has been a considerable decrease within recent years in the secular change of the magnetic declination, and in Western Australia there has been a considerable increase. There are no data available as to how the secular change is altering in the southern Indian Ocean between South Africa and Australia. The magnetic charts for this area are therefore based at present upon very uncertain extrapolations. In other areas, where the magnetic elements are known at present with reasonable accuracy, the extrapolated values would become less and less reliable in the course of time, in the absence of further observations, such as were provided by the Carnegie, to serve as a control on the changes in the secular variations.

In view of the fact that Great Britain is the principal maritime nation, the British Government has accepted the responsibility of providing accurate magnetic data at sea, and a non-magnetic ship is to be built, equipped and operated for this purpose by the Admiralty. The ship is to be known as the Royal Research Ship Research (R.R.S. Research), and she will fly the Blue Ensign and Jack with the yellow Admiralty anchor in the fly.

The plans for the new ship have been prepared at the Admiralty and it is hoped that the construction will be commenced shortly. The Department of Terrestrial Magnetism of the Carnegie Institution of Washington not only placed at the disposal of the Admiralty all information with regard to the construction and the instrumental and other equipment of the Carnegie, but also generously gave the services of Mr. W. J. Peters as consultant, without charge. The experience and advice of Mr. Peters, who commanded the Carnegie on her first two cruises, have been of the greatest value in the design of the ship and of her equipment.

The R.R.S. Research will be somewhat larger than the Carnegie. She will have a displacement of 650 tons and will be brigantine rigged. She will be provided with a single screw Diesel engine and will carry sufficient oil fuel to give a radius of action of about 2,000 miles at 6 knots. Her cables will be of bronze, instead of the hemp rope used in the Carnegie, and to some extent brass or bronze will take the place of wood. She will carry a total complement of 31 , including the commanding officer, three deck officers, three scientific workers, a surgeon (who will also be a scientist) and an engineer.

The work of the R.R.S. Research will not be restricted solely to magnetic observations. She will undertake observations of atmospheric elec- tricity. Such observations are particularly valuable at sea, where the air is less contaminated by suspended impurity than it is on land. It may be recalled that it was by means of observations on the Carnegie that it was established that the maximum potential gradients are related to Universal Time and not to the local time of the place of observation. The Research will be provided with an oceanographic winch and motor for oceanographic work, will carry an echo depth sounding gear, and will also make meteorological observations, including upper air observations by means of pilot balloons.

The principal magnetic instruments for observations at sea will be a marine collimating compass for observations of declination; a sea-deflector, for observations of the horizontal intensity ; and a marine dip inductor for observation of the dip. The collimating compass is a modification of the standard marine liquid compass. The magnet system carries four concave speculum mirrors, adjusted so that their optical axes are in the direction of the four cardinal compass points. A scale is mounted in the focus of each mirror. The four scales are carried on arms attached to the magnet system. The angle between the sun, when at low altitude, and one or other of the four compass points, as defined by the scale images, is measured with a sextant, the scales being viewed through windows in the compass bowl. This observation provides the means of calculating the magnetic declination. The compass will be mounted in such a position that it will have as clear a view of the horizon as possible.

The sea deflector consists of a marine compass, provided with permanent attachments, whereby a deflecting magnet can be mounted in a horizontal position and vertically above or below the compass magnet system. The bowl is rotated until the deflecting magnet is perpendicular to the compass magnet, as shown by the reading of the card. The angle of deflection is read on a graduated scale on the edge of the bowl. The deflector is mounted in an observatory adjacent to, and forward from, the chart room, in which is the standard compass. As the observer at the deflector reads off the angle of deflection, a second observer at the standard compass reads off the direction of the ship's head. The horizontal intensity is proportional to the cosecant of the deflection. The constant of proportionality is determined periodically by simultaneous observations ashore, with the sea deflector and land magnetometer.

The marine earth-inductor follows the general design of earth-inductors, but is provided with a special gimbal stand that is not affected by the rotation of the coils. It is important, for observations 
at sea, that it should be driven at a constant speed, and a special tuning-fork controlled rotary converter, situated in the after part of the vessel and driving through an articulated phosphorbronze shaft, will be provided to ensure this. Two galvanometers, one of the moving coil type, with short period, and the other of the string type will be provided and experience will be gained at sea of the relative suitabilities of the two types. The earth-inductor will be mounted in an after observatory.

Portable instruments for land observations, at fixed magnetic observatories and elsewhere, will also be carried. The designs of the instruments have been based on the Carnegie Institution designs, with such modifications as were suggested by experience on the Carnegie or as seemed desirable for various reasons.

The magnetic observations on the R.R.S. Research will be made primarily in the interests of navigation. But they will provide at the same time valuable information about the earth's magnetism, which is needed for the investigation of such matters as the non-potential portion of the earth's field and the line integrals around closed contours on the earth's surface.

\title{
Body Orientation of the Lower Crustacea (Branchiopoda)
}

\author{
By John H. Lochhead, University Museum of Zoology, Cambridge
}

\begin{abstract}
A MONG the Branchiopoda it is now well known A that the Anostraca swim normally lying on the back, while the Notostraca swim with the back directed upwards. Orientation is also constant among the Cladocera, but there are here considerable differences between genera.

Four possible controlling factors have been suggested. These are the aeration of the water, gravity, the surface resistance of the animal, and light.
\end{abstract}

Lowndes ${ }^{1}$ and Wertheim ${ }^{2}$ hold that the limbs of Anostraca, which are doubtless respiratory, are normally directed upwards because the upper layers of water are best aerated. This view, however, cannot apply to the Notostraca. Nor could orientation be controlled in this way except perhaps very near the water surface, since the differences in aeration above and below a swimming animal must normally be too small to be detected. It is true, however, that both Anostraca and Notostraca often come up and beat their limbs just below the surface film, the Notostraca specially turning over on to their backs for this purpose. It has been widely stated that this occurs especially when the oxygen content of the water is low. It may thus well be a respiratory phenomenon, though Mathiass has shown that the oxygen requirements of Artemia are surprisingly small. In any event, however, the habit is quite distinct from the more usual swimming of the animals farther below the surface.

Control of orientation by gravity may occur in two ways. There may be automatic control, the centre of gravity of the animal being so placed that a constant attitude tends to be maintained independent of muscular effort. The factor of the resistance offered by the surface shape of the animal to the water may also play a part here. Or there may be nervous control due to the effect of gravity on special sense receptors, the position maintained by the animal being then not necessarily the stable one with respect to the automatic forces just mentioned.

Surface resistance is a factor of special importance in the Cladocera, because of the regular rest pauses which characterize their swimming. But in the Anostraca and Notostraca, considered for the sake of simplicity only when swimming or floating more or less horizontally, the effect of surface resistance on dorso-ventral orientation must be small. R. T. Muller", however, has shown that for Anostraca the effect due to the centre of gravity may be important. It has long been known that in water the anostracan body sinks back downwards. This might be due to the position of the centre of gravity, or to surface resistance. Müller showed that it is due to both these factors. He placed both fixed and narcotized Tanymastix in sugar solution of the same specific gravity as that of the animals, and found that they then lay floating in the solution back downwards. This could be due only to the position of the centre of gravity. He then raised the specific gravity of the solution until the animals rose up fairly rapidly towards the surface; they did so back upwards, surface resistance overcoming the force exerted by the centre of gravity. Thus when an anostracan sinks in water, both forces tend to keep the back downwards. For the Notostraca, such careful experiments have not been done; but Seifert ${ }^{5}$ has shown that a dead Apus also sinks in water back downwards. Probably this is due to the same 